\title{
Spoken and Written Narrative in Persian-Speaking Students Who Received Cochlear Implant and/or Hearing Aid
}

\author{
Peyman Zamani ${ }^{1}$ - Zahra Soleymani ${ }^{2}$. Vahid Rashedi ${ }^{3, \star} \cdot$ Farhad Farahani ${ }^{4} \cdot$ Gohar Lotfi ${ }^{4,5} \cdot$ Mohammad Rezaei $^{4,5}$ \\ ${ }^{1}$ Hearing and Speech Research Center, Ahvaz Jundishapur University of Medical Sciences, Ahvaz; \\ ${ }^{2}$ Department of Speech Therapy, School of Rehabilitation, Tehran University of Medical Sciences, Tehran; \\ ${ }^{3}$ Iranian Research Center on Aging, University of Social Welfare and Rehabilitation Sciences, Tehran; \\ ${ }^{4}$ Hearing Disorders Research Center and ${ }^{5}$ Department of Speech Therapy, Faculty of Rehabilitation Sciences, Hamadan University of \\ Medical Sciences, Hamadan, Iran
}

Objectives. To compare narrative skills between fourth and fifth grades of Persian-speaking students with hearing impairments and typical hearing students of the same grade and also to evaluate the effects of group, sex, hearing age, and educational grade of the students on their spoken/written narrative performance.

Methods. The subjects were 174 students aged 10-13 years, 54 of whom wore cochlear implants, 60 suffered from moderate to severe hearing losses and wore hearing aids, with the remaining 60 students being typical hearing in terms of the sense of hearing. The micro- and macrostructure components of spoken and written narrative were elicited from a pictorial story (The Playful Little Elephant) and then scored by raters.

Results. Compared to the typical hearing, the students with hearing impairments had significantly lower scores in all of the microstructure components of narratives. However, the findings showed no significant difference among different groups in macrostructure components of narratives. It was also revealed that the students had equal performance in spoken and written narrative. Finally, factor analysis manifested that group, sex, hearing age, and educational level of children might alter the outcome measures in various interactions.

Conclusion. Although cochlear implantation was more effective than hearing aid on spoken and written narrative skills, the Persian-speaking students with hearing impairments were seen to need additional trainings on microstructure components of spoken/written narrative.

Keywords. Narration; Cochlear Implants; Hearing Aids

\section{INTRODUCTION}

- Received August 6, 2017

Revised February 24, 2018

Accepted March 26, 2018

- Corresponding author: Mohammad Rezaei

Department of Speech Therapy, Faculty of Rehabilitation Sciences,

Hamadan University of Medical Sciences, St. no. 1, Hamadan, Iran

Tel: +98-919-711-8547, Fax: +98-813-838-1571

E-mail: m_r_st@yahoo.com

*Vahid Rashedi is now working at Tehran Psychiatric Institute, School of Behavioral Sciences and Mental Health, Iran University of Medical Sciences, Tehran, Iran.
Affecting the process of acquiring primary language skills, hearing loss can delay and disturb language development at subsequent stages [1]. Three of each 1,000 newborn Iranian infants are engaged with hearing impairment, more than $50 \%$ of whom are referred for receiving cochlear implantation (CI) [2]. For 30 years, significant improvements have been reported in terms of receptive and expressive lexicon [3,4], mean length of utterance [5], morpho-syntactic complexities [6], speech intelligibility $[7,8]$, and speech perception [6] by using cochlear implants in

Copyright $\odot 2018$ by Korean Society of Otorhinolaryngology-Head and Neck Surgery.

This is an open-access article distributed under the terms of the Creative Commons Attribution Non-Commercial License (http://creativecommons.org/licenses/by-nc/4.0)

which permits unrestricted non-commercial use, distribution, and reproduction in any medium, provided the original work is properly cited. 
the children with severe-to-profound hearing impairments. Despite the fact that those children with hearing impairments who wear $\mathrm{CI}$ can rapidly produce sentences and follow auditory-oral rehabilitation, they are consistently classified as children with delayed higher-level language skills $[3,6]$.

Narrative skill is a high-level sophisticated language skill which enables the child to tell real events or self-fictional intentions [9]. Generally, it can be stated that development of narrative skill begins at about the age 3 and continues as the child naturally communicates verbally with adults during his or her childhood and thereafter in adolescence ages [10]. In children and students, narrative skill is usually studied and assessed in the frameworks of spoken and written storytelling [11]. Students' ability to narrate their wishes, knowledge, ideas, events, and stories, whether in a spoken or written form, plays a notable role in their success and advance in mainstream school, friendship, and social participation. In fact, narrative skill can associate the primary cognitive-linguistic skills to social communications [12]. Although the research on the narrative ability of the children with hearing impairments is scarce, researchers believe that lack of linguistic knowledge, specifically in terms of syntax and morphology [13], limitations in abstract lexicon [14], and deficits in meta-cognitive information for integration of holistic comprehension and inference are caused by lack of auditory confronting and auditory experiences with stories [15] and might negatively affect hearing-impaired children's narrative ability. According to the Iranian educational program for mainstream schools, formally, students begin to learn written composition in the third grade of elementary school. It means that since this grade of elementary school, students must describe $\mathrm{real} /$ concrete or fictional/abstract topics and/or rewrite alreadyheard stories on the paper. This educational program has been founded on the presumption that all of the elementary students had already attained preliminaries of language skills development [16]. However, it is well known that those school-age children wearing cochlear implants or hearing aids have difficulties in literacy which are caused by the associated lags in primary language acquisition [17].

On the other hand, we know that speech production is influenced by various language tasks $[18,19]$, and narrative writing is a secondary form of speech which related to it. So, it can be hy-

\section{H I G H L I G G H T S}

- The students with hearing impairments had lower scores in narrative skills than typical hearing peers.

- The cochlear implantation was more effective than hearing aid on spoken and written narrative skills.

- Hearing deprivation may limit microstructures of spoken/written narration in students who received cochlear implant or hearing aid relative to typical hearing peers. pothesized that spoken/written narrative tasks may affect children's narrative performance. That is, narrative writing is more than just spelling some words or writing a couple of sentences or associated clauses. In addition to motor abilities for writing, students need a capability to perform quick phonological processing for sound-to-letter conversion [20] as well as knowledge of vocabulary, word order rules in sentence, subject-verb agreements, and clause connection for transferring key ideas and concepts in a successful written composition [12]. Some of these instances (such as sound-to-letter conversion or word order) may not be present in a fully-spoken narrative task. So, it seems that narrative writing tasks are more complicated than spoken ones. Although limited research has been done on the comparison between spoken and written narrative tasks in school-age children, previous findings revealed that in comparison to normal peers, the students with delayed language development tend to write texts with more grammatical and lexical errors $[20,21]$, with their written composition being of less syntactic coherence [12].

Due to the above-mentioned qualifications, it can be stated that the students who use assistive listening devices (similar to children with language impairments) have problems in various components of high-level sophisticated narrative skill; to the best of our knowledge, only a few studies have been reported on this problem among Persian-speaking students. By the way, the advantages of using cochlear implants relative to hearing aids for narrative skills have not been investigated in hearing impaired Persian-speaking students. Therefore, the present study was implemented with the following aims: (1) to determine scores of narrative skill (in the spoken and written form) among Persian-speaking cochlear-implanted (CI), hearing-aided (HA), and typical hearing (TH) fourth and fifth grade students and (2) to compare the students' spoken and written narrative skills based on their groups, sex, hearing age, and educational grades.

\section{MATERIALS AND METHODS}

\section{Participants}

In this cross-sectional study, 114 students with hearing impairments (either using cochlear implants or hearing aids) were selected from 13 schools of Hamadan City in western Iran. These subjects were recruited based on inclusion criteria: prelingual hearing loss, having moderate-to-severe hearing loss for students with hearing aids, $\mathrm{CI}$ before the age 5 , studying in the fourth or fifth grade of mainstream school educations, having normal intellectual abilities, and having speech intelligibility more than $80 \%$. Students with signs of disorders such as delayed cognitive development, attention deficit, learning disability in literacy skills, and additional disabilities (e.g., oral and limb motor disorders such as cerebral palsy) were excluded. All of the students were evaluated by Persian version of Wechsler intelli- 
Table 1. Description of participants' demographic characteristics

\begin{tabular}{|c|c|c|c|c|c|}
\hline \multirow{2}{*}{ Variable } & \multicolumn{3}{|c|}{ Group } & \multirow{2}{*}{ Test value } & \multirow{2}{*}{$P$-value } \\
\hline & $\mathrm{Cl}(\mathrm{n}=54)$ & $\mathrm{HA}(n=60)$ & $\mathrm{TH}(\mathrm{n}=60)$ & & \\
\hline Age (yr) & $11.29 \pm 0.95$ & $11.91 \pm 1.12$ & $10.90 \pm 0.90$ & $F=1.38$ & 0.092 \\
\hline Education & & & & $\chi^{2}=0.26$ & 0.113 \\
\hline Fourth grade & $30(55.6)$ & $30(50)$ & $30(50)$ & & \\
\hline Fifth grade & $24(44.4)$ & $30(50)$ & $30(50)$ & & \\
\hline Sex & & & & $\chi^{2}=0.18$ & 0.192 \\
\hline Female & $26(48.1)$ & $30(50)$ & $30(50)$ & & \\
\hline Male & $28(51.9)$ & $30(50)$ & $30(50)$ & & \\
\hline Hearing age (yr) & $8.98 \pm 0.96$ & $7.07 \pm 0.99$ & Normal & $t=2.59$ & 0.011 \\
\hline IQ score & $101.81 \pm 3.51$ & $100.90 \pm 3.22$ & $102.11 \pm 2.59$ & $F=0.11$ & 0.513 \\
\hline Language score & $93.8 \pm 9.5$ & $91.1 \pm 9.9$ & $100.7 \pm 8.2$ & $F=3.29$ & 0.016 \\
\hline Hearing threshold without device & & & & & - \\
\hline Mild-moderate $(>30 \&<70 \mathrm{~dB}$ ) & - & 11 & Normal & & \\
\hline Severe $(>70 \&<85 \mathrm{~dB})$ & - & 47 & Normal & & \\
\hline Profound (>90 dB) & 54 & 2 & Normal & & \\
\hline Ear implanted & & & & & - \\
\hline Left & 12 & - & - & & \\
\hline Right & 42 & - & - & & \\
\hline Laterality of hearing device & & & & & - \\
\hline Unilateral & 53 & 23 & - & & \\
\hline Bilateral & 1 & 37 & - & & \\
\hline
\end{tabular}

Values are presented as mean \pm standard deviation or number (\%).

$\mathrm{Cl}$, cochlear-implanted; $\mathrm{HA}$, hearing-aided; $\mathrm{TH}$, typical hearing; IQ, intelligence quotient .

gence scale for children [22], Persian speech intelligibility measurement [23], Persian version of test of language development [24], and teacher questionnaire of learning disabilities prior to the beginning of narrative sampling. The intelligence quotient (IQ) test, physical examinations, and speech and language assessments were accomplished by pediatric psychiatrics and speech pathologist in the Cochlear Implant Center of Hamadan University of Medical Sciences. The Persian version of speech intelligibility measurement is included 29 mono- or multisyllabic pictorial words, which computes Persian-speaking children's speech intelligibility percentage. Interclass correlation coefficient reliability of this test was 0.89 [23]. The children with CI were corresponded to the HA students based on their sex, chronological age, grade of school, language (Persian speaking), and area of residence (Hamadan City in western Iran). Of these, 60 students wearing hearing aids and $54 \mathrm{CI}$ students were selected ultimately. Also, based on chronological age, IQ, sex, and grade of school, $60 \mathrm{TH}$ students with healthy sense of hearing were selected along with the hearing-impaired students. This group of students served as criterion-reference for comparison purposes. Table 1 summarizes demographic characteristics of the participants in terms of chronological age, level of education, sex, hearing age (the length of age since the hearing device fitting for child), IQ, language score, hearing threshold without device, and laterality of hearing device. None of the students attended special settings or deaf schools. All the CI students communicated orally, but $80 \%$ of the students with hearing aids used oral com- munication, with the remaining $20 \%$ of them using total communication. Their parents were healthy in terms of the sense of hearing. This study was approved by the Ethical Committee of Hamadan University of Medical Sciences (IR.UMSHA. REC.1395.381) and conducted in accordance with the Declaration of Helsinki (1975).

\section{Instruments and procedures}

Evaluation of a child's narrative skill usually involves the assessment of micro- and macrostructure components of the skill. Macrostructure of narration refers to its content and overall characteristics, such as the key information and the sequence of adventures. Also, microstructure of narration includes several morphosyntactic and grammar characteristics that allow researchers to analyze children's language form/function [25]. Table 2 describes some of the important micro- and macrostructure components of narration studied in this research [11,18,26,27].

Spoken and written narrative skills were sampled by a pictorial story entitled as "The Playful Little Elephant." The story consists of 10 pictures and is developed based on story grammar elements (setting, problem, action, consequence, and ending) for narrative assessment in Persian-speaking children [28]. Involving an event for an elephant and her friend (a giraffe) near a pool, the story is appropriate and comprehensible for children. In this narrative task, the students were asked to tell the story upon the wordless book and then to write the story 2 weeks later. In fact, at first, story-telling and story-writing directions were 
Table 2. Description of the micro- and macrostructure components of narrative

\begin{tabular}{|c|c|}
\hline Component & Description \\
\hline \multicolumn{2}{|l|}{ Microstructure } \\
\hline ATL & $\begin{array}{l}\text { A T-unit is a free clause addition any it's bound clauses or phrases in spoken or written narrative. The total number of words } \\
\text { divided by the number of T-units is the ATL [26] (e.g., The little elephant that was very playful runs toward the ball and she } \\
\text { slips on the ground. ATL }(w)=17 / 2=8.5) \text {. }\end{array}$ \\
\hline SI & $\begin{array}{l}\text { Sum of the total number of clauses divided by the number of T-units [26] (e.g., Elephant, who was regretful, apologized for her } \\
\text { mistake and then she promised that walk slowly beside pool. SI=4/2=2) }\end{array}$ \\
\hline Cohesive marker & $\begin{array}{l}\text { The linguistic markers that connect and associate the separated clauses to make them an integrated narrative unit (e.g., but, } \\
\text { so, and then, because, why, that) [26] }\end{array}$ \\
\hline Narrative cohesion & The total number of complete cohesive markers in a narrative sample divided by the total number of cohesive markers [11] \\
\hline Accuracy performance & The ratio (in percent) of semantically and syntactically errorless clauses relative to the total number of clauses [18] \\
\hline \multicolumn{2}{|l|}{ Macrostructure } \\
\hline Main information & Representation of complete, enough, elaborative, and detailed information in narrative [27] \\
\hline Topic maintenance & Child must keep central theme and continue the main topic of story [27]. \\
\hline Event sequencing & Temporal observance of the order of events of narrative based on a reasonable arrangement [27] \\
\hline Total score & Sum of three items of macrostructures \\
\hline
\end{tabular}

ATL, average T-unit length; w, word; SI, subordination index.

introduced to the students by the researchers. Then, each student proceeded to tell the target story while his/her narrative voice was being recorded. After 2 weeks, each of the students was asked to write the story on a piece of paper within the same time. A total of 10 and 15 minutes were dedicated to story-telling and story-writing, respectively. All of the spoken and written samples were administered by trained speech-language pathologists in quiet locations. Since the task was to narrate in either of two spoken and written forms, the students should have begun and terminated the story themselves. If examinees had difficulties in telling/writing the story, the examiners prompted them with sentences such as "tell/write about what happen in the picture" or "tell/write more." The children's storytelling was transcribed by the first author before being given to two coders for coding and scoring the micro- and macrostructure components of narrative. The raters who were blind concerning children's characteristics received the samples for coding and scoring of the micro- and macrostructure components of the narrative. All samples were coded by coders independently. Computed by the following formula [29], the percentage of interraters agreement more than $95 \%$ was taken as acceptable for each of the components of narrative. The percentage of intrarater agreement was also calculated in this manner. It means that each rater coded spoken samples two times with a 2-week interval.

Inter- or intrarater agreement $=$ [agreements $/$

(agreements+disagreements) $] \times 100$

Also, the same procedure was followed to analyze language samples of the children's written narrative skill, except that transcription of the children's writings was not required. The percentage of inter- and intrarater agreement for micro- and macrostructure components of spoken and written narrative were high-good (from 95\% to $98 \%$ ).

\section{Statistical analysis}

After checking the normality of distribution of data with onesample Kolmogorov-Smirnov test and the homogeneity of variances by Mauchly's test, the mean values of the components of spoken and written narrative in three groups were compared using one-way analysis of variance (ANOVA) test to betweengroup comparisons. Following that, we used a (three groups: $\mathrm{CI}$ vs. HA vs. TH $) \times($ two sexes: female vs. male $) \times($ two hearing age: normal vs. having deprivation $) \times$ (two educational grades: fourth vs. fifth) four-way repeated measures ANOVA with followed post hoc Bonferroni adjustment test with groups, sexes, hearing age, and educational grades as between-subject factors and structures of narrative as within-subject factor for each sample on eight measures (the average T-unit length [ATL], subordination index [SI], cohesive markers, the percentage of narrative cohesion, the percentage of accuracy performance, main information, topic maintenance, event sequencing). The main effects as well as interaction effects of the variables were computed. If a main effect or interaction of each factor was significant, it was reported. The level of statistical significance was set at $P \leq 0.05$. Analyses were performed using SPSS ver. 17.0 (SPSS Inc., Chicago, IL, USA).

\section{RESULTS}

\section{General comparisons}

Both groups of CI and HA had significantly lower scores in all of the microstructure components of spoken/written narrative as compared to the TH students, while students with $\mathrm{CI}$ attained higher the mean values in all of the microstructure components of spoken/written narrative compared to the HA students (Table 3). The post hoc Bonferroni adjustment test showed that there were significant differences between two groups of CI and HA stu- 
Table 3. Microstructure components of spoken and written narrative in studied groups

\begin{tabular}{|c|c|c|c|c|c|}
\hline \multirow{2}{*}{ Variable } & \multicolumn{3}{|c|}{ Group } & \multirow{2}{*}{$P$-value } & \multirow{2}{*}{ Effect size $\left(\eta^{2}\right)$} \\
\hline & $\mathrm{Cl}(\mathrm{n}=54)$ & $H A(n=60)$ & $\mathrm{TH}(\mathrm{n}=60)$ & & \\
\hline \multicolumn{6}{|l|}{ Spoken narrative } \\
\hline ATL & $6.23 \pm 1.38$ & $4.88 \pm 0.78$ & $9.19 \pm 1.22$ & $<0.001$ & 0.331 \\
\hline $\mathrm{SI}$ & $1.54 \pm 0.38$ & $1.45 \pm 0.44$ & $1.72 \pm 0.40$ & 0.031 & 0.254 \\
\hline Cohesive marker & $14.33 \pm 7.28$ & $8.08 \pm 4.49$ & $20.02 \pm 4.14$ & $<0.001$ & 0.404 \\
\hline Narrative cohesion & $76.99 \pm 22.23$ & $49.19 \pm 23.13$ & $82.12 \pm 8.04$ & $<0.001$ & 0.302 \\
\hline Accuracy performance & $77.02 \pm 14.84$ & $61.02 \pm 19.69$ & $88.69 \pm 8.88$ & $<0.001$ & 0.297 \\
\hline \multicolumn{6}{|l|}{ Written narrative } \\
\hline ATL & $5.26 \pm 1.32$ & $4.42 \pm 0.68$ & $8.34 \pm 1.16$ & $<0.001$ & 0.319 \\
\hline $\mathrm{SI}$ & $1.40 \pm 0.30$ & $1.38 \pm 0.24$ & $1.47 \pm 0.25$ & 0.022 & 0.275 \\
\hline Cohesive marker & $12.22 \pm 7.66$ & $6.27 \pm 4.55$ & $16.92 \pm 4.50$ & $<0.001$ & 0.344 \\
\hline Narrative cohesion & $72.88 \pm 25.39$ & $46.76 \pm 24.28$ & $81.59 \pm 7.17$ & $<0.001$ & 0.323 \\
\hline Accuracy performance & $73.12 \pm 15.67$ & $57.81 \pm 21.19$ & $87.87 \pm 7.77$ & $<0.001$ & 0.310 \\
\hline
\end{tabular}

Values are presented as mean \pm standard deviation.

$\mathrm{Cl}$, cochlear-implanted; HA, hearing-aided; TH, typical hearing; ATL, average T-unit length; SI, subordination index.

Table 4. Macrostructure components of spoken and written narrative in studied groups

\begin{tabular}{|c|c|c|c|c|c|}
\hline \multirow{2}{*}{ Variable } & \multicolumn{3}{|c|}{ Group } & \multirow{2}{*}{$P$-value } & \multirow{2}{*}{ Effect size $\left(\eta^{2}\right)$} \\
\hline & $\mathrm{Cl}(\mathrm{n}=54)$ & $H A(n=60)$ & $\mathrm{TH}(\mathrm{n}=60)$ & & \\
\hline \multicolumn{6}{|l|}{ Spoken narrative } \\
\hline Main information & $11.20 \pm 1.76$ & $10.53 \pm 1.83$ & $11.80 \pm 1.50$ & 0.081 & 0.041 \\
\hline Topic maintenance & $4.65 \pm 0.55$ & $4.42 \pm 0.78$ & $4.69 \pm 0.46$ & 0.075 & 0.054 \\
\hline Event sequencing & $7.02 \pm 1.43$ & $6.93 \pm 1.72$ & $7.95 \pm 1.11$ & 0.071 & 0.054 \\
\hline Total score & $23.19 \pm 3.83$ & $22.84 \pm 3.85$ & $24.29 \pm 2.11$ & 0.090 & 0.040 \\
\hline \multicolumn{6}{|l|}{ Written narrative } \\
\hline Main information & $10.89 \pm 1.56$ & $10.20 \pm 1.69$ & $11.40 \pm 1.39$ & 0.077 & 0.050 \\
\hline Topic maintenance & $4.52 \pm 0.72$ & $4.23 \pm 0.81$ & $4.55 \pm 0.55$ & 0.069 & 0.049 \\
\hline Event sequencing & $7.02 \pm 1.38$ & $6.50 \pm 1.64$ & $7.59 \pm 1.24$ & 0.110 & 0.022 \\
\hline Total score & $22.39 \pm 3.41$ & $21.93 \pm 3.82$ & $23.03 \pm 2.18$ & 0.081 & 0.038 \\
\hline
\end{tabular}

Values are presented as mean \pm standard deviation.

$\mathrm{Cl}$, cochlear-implanted; $\mathrm{HA}$, hearing-aided; $\mathrm{TH}$, typical hearing.

dents for all microstructure components of spoken/written narrative $(P<0.05)$ except SI $(P=0.110)$ which was equivalent in them.

In comparison with $\mathrm{TH}$, students with $\mathrm{CI}$ and $\mathrm{HA}$ did not show statistical differences in macrostructure components, neither in spoken form nor written (Table 4). There were also no significant differences between spoken and written narrative within groups $(P>0.05)$.

\section{Main effects and interaction effects on microstructure components of narratives}

Regardless groups, the hearing age-related difference was also significant on the microstructure components of spoken/written narrative where the post hoc Bonferroni adjustment test showed that the HA group performed worse than the $\mathrm{CI}$ and $\mathrm{TH}$ groups on ATL $(Z=-2.943, P<0.001)$, number of cohesive markers $(Z=$ $-2.869, P<0.001)$, narrative cohesion $(Z=-2.882, P<0.001)$, and accuracy performance $(Z=-3.044, P<0.001)$. Although there were no other significant main effects on the microstructure out-
Table 5. Results of the interaction effects analysis for demographic factors on microstructure components of spoken and written narrative

\begin{tabular}{|c|c|c|c|}
\hline Interaction effect & $F_{(2,162)}$ & $P$-value & Effect size $\left(\eta^{2}\right)$ \\
\hline ATL $\times$ group $\times$ educational level & 4.36 & $<0.001$ & 0.256 \\
\hline $\begin{array}{l}\text { Cohesive marker } \times \text { group } \times \\
\text { educational level } \times \text { sex }\end{array}$ & 3.95 & $<0.045$ & 0.186 \\
\hline $\begin{array}{l}\text { Narrative cohesion } \times \text { group } \times \\
\text { educational level } \times \text { sex }\end{array}$ & 6.37 & 0.013 & 0.155 \\
\hline $\begin{array}{l}\text { Accuracy performance } \times \text { group } \times \\
\text { educational level } X \text { sex }\end{array}$ & 4.39 & 0.040 & 0.151 \\
\hline
\end{tabular}

ATL, average T-unit length.

come measures, analysis showed interaction among some factors on the microstructure outcome measures of spoken/written narrative, which those are presented in Table 5.

The group $\times$ educational level interaction-related difference was significant on the ATL of spoken/written narrative where the post hoc Bonferroni adjustment test showed that the fourth 
HA students performed lower than the other groups on ATL $(\mathrm{Z}=-2.543, P<0.011)$, and the fifth $\mathrm{TH}$ students performed higher than the other groups on ATL $(\mathrm{Z}=2.943, P<0.005)$.

The group $\times$ educational level $\times$ sex interaction-related difference was significant on the number of cohesive markers, narrative cohesion, and accuracy performance of spoken/written narrative where the post hoc Bonferroni adjustment test showed that the fifth TH girl students performed higher than the other students on the number of cohesive markers $(\mathrm{Z}=2.661, P=$ 0.010), narrative cohesion $(Z=2.505, P=0.011)$, and accuracy performance $(\mathrm{Z}=3.062, P=0.009)$ respectively, and the fourth HA boy students performed lower than the other students on the number of cohesive markers $(\mathrm{Z}=-2.499, P=0.010)$, narrative cohesion $(\mathrm{Z}=-2.445, P=0.012)$, and accuracy performance $(Z=-2.776, P=0.008)$, respectively. We did not see any significant interaction effect of factors on SI of spoken and written narratives.

\section{Main effects and interaction effects on macrostructure components of narratives}

Analysis revealed no significant main effects of demographic factors on all of the macrostructure components of spoken/written narrative $\left(P>0.05, \eta^{2}<0.055\right.$, power $\left.=0.238\right)$. It means that demographic factors singly had no effects on macrostructures alteration. However, the analysis showed the following significant interactions among macrostructure components of spoken/written narrative (Table 6).

The sex $\times$ educational level interaction-related difference was significant on the main information, topic maintenance, event sequencing, and total score of spoken/written narrative where the post hoc Bonferroni adjustment test showed that the fifth girl students performed higher than the other students on main information $(\mathrm{Z}=2.091, P=0.045)$, topic maintenance $(\mathrm{Z}=2.095$, $P=0.045)$, event sequencing $(Z=2.088, P=0.046)$, and total score of macrostructures $(\mathrm{Z}=2.169, P=0.019)$, respectively. Also, the fourth boy students performed lower than the other students on main information $(\mathrm{Z}=-2.009, P=0.045)$, topic maintenance $(Z=-2.045, P=0.022)$, event sequencing $(Z=-2.191$, $P=0.011)$, and total score of macrostructures $(Z=-2.116, P=$ $0.018)$, respectively. No other statistically significant interaction

Table 6. Results of the interaction effects analysis for demographic factors on macrostructure components of spoken and written narrative

\begin{tabular}{lccc}
\hline Interaction effect & $F_{(2,162)}$ & $P$-value & Effect size $\left(\eta^{2}\right)$ \\
\hline $\begin{array}{l}\text { Main information } \times \text { sex } \times \\
\quad \text { educational level }\end{array}$ & 5.27 & 0.024 & 0.199 \\
$\begin{array}{c}\text { Topic maintenance } \times \operatorname{sex} \times \\
\text { educational level }\end{array}$ & 3.89 & 0.039 & 0.183 \\
$\begin{array}{c}\text { Event sequencing } \times \text { sex } \times \\
\text { educational level }\end{array}$ & 4.66 & 0.033 & 0.175 \\
$\begin{array}{c}\text { Total score } \times \text { sex } \times \\
\text { educational level }\end{array}$ & 6.07 & 0.020 & 0.190 \\
\hline
\end{tabular}

effects on macrostructure components of spoken/written narrative were observed.

\section{DISCUSSION}

In this study, spoken and written narrative skills of $54 \mathrm{CI}$ students and $60 \mathrm{HA}$ students were compared to $60 \mathrm{TH}$ peers. All students were in fourth or fifth grades of school at the time of sampling, and three groups were corresponded based on chronological age, sex, and IQ score. However, the students were significantly different in order of hearing age. The hearing age of the CI students was significantly higher than HA students. As predicted, this factor can impose on the outcomes. We will discuss this issue later in the paper.

The first objective of this study was to determine mean scores of micro- and macrostructure components of narrative, in both spoken and written forms, within each group of the Persianspeaking students. The microstructure of narrative divided to five components (ATL, SI, cohesive markers, narrative cohesion, and accuracy performance); the mean scores of these items, in both forms, were significantly greater in the TH students, as compared to the hearing-impaired students. The ATL and SI are two criterion-references for syntactic complexity of narration. With respect to morpho-syntactic view, the greater these items, the more complicated will be the corresponding narration. The ATL-based syntactic complexity of narration depends on the total number of words and total number of correct verbs in spoken or written narration. It means that, with increasing the number of functional and content words (especially verbs) in a narration, we expect higher ATL [27]. Since as compared with TH students, the hearing-impaired students (especially hearingaided) had periods of hearing deprivation, they could not acquire their abstract lexicon concordant with normal development, and they tended to use more simple words and sentences to describe an event [30]. So, syntactic complexity of spoken or written narration in the TH students was significantly more than the students with hearing impairments. The ATL also was significantly higher in CI students than HA students, while similar SI was obtained for these two groups. Based on the use of compound sentences, complex clauses or simple sentences, the SIbased syntactic complexity of narration can change. If the number of bound clauses and phrases for each T-unit is low, the ratio of SI will decrease, thereby indicating simpler syntactic complexity of the narration [27]. As noted above, the mean of SI in CI students was greater than that of HA students, but the difference was not significant. A probable reason for the lower ATL score and SI in students with hearing impairments compared to $\mathrm{TH}$ students might be the fact that they tend to use more of simple sentences as they suffer from hearing disorders. This matter, however, needs further investigation.

Cohesive markers and narrative cohesion components must 
be interpreted simultaneously because the cohesive markers are indeed the makers of narrative cohesion. If cohesive markers are absent, separated sentences and clauses may fail to deliver the concepts and purposes of the narration or story. Consequently, it is possible that listeners cannot correctly infer from the children's narration. In fact, adequate comprehension of narration depends on several parameters such as words, sentences and grammar [31], the speaker's social and cultural knowledge [32], and the speaker's characteristics [33]. The results showed that the students with hearing impairments have used cohesive markers significantly less frequently than their TH peers, thereby lowering their percentage of narrative cohesion. Some researchers believe that cohesion percentages of less than $70 \%$ indicate narrative deficit [11]. Mean values of the spoken/written narrative cohesion percentage of HA students were well below $70 \%$ $(<50 \%$ in spoken and $<47 \%$ in written narrative). Besides the mean frequency of cohesive markers, this finding indicated that HA students compared to $\mathrm{CI}$ and TH students had difficulty in using morpho-syntactic components to tie sentences and clauses of narration.

Accuracy performance can be considered as an indication of general quality of microstructure components of narration as it returns percentages of semantic and morpho-syntactic correctness of clauses. In fact, accuracy performance emphasizes on the quality of narrative microstructures rather than quantity and the number of them. Accuracy performance is a function of correct use of the conjunctions, relatives, prefixes, suffixes, tense of verbs, and other morpho-syntactic microstructures [18]. Despite the equality of SI between CI students and HA students (using the same number of compound sentences and complex clauses by them), accuracy performance score in HA students was significantly lower than $\mathrm{CI}$ students. Therefore, it might be assumed that, in comparison to CI students, HA students need narrative cohesion trainings to increase the number of complex morphosyntactic structures. Both of these groups had significantly lower scores than the TH students. So, students with hearing impairments must be trained for narrative microstructures (either spoken or written form).

The macrostructure of narration contained three components (main information, topic maintenance, and event sequencing). The results showed no statistically significant difference among the three groups in terms of the macrostructure. Although the students had noticeable differences in microstructure components of spoken and written narrative, they could equally transfer the main idea and concepts of the story to audiences and addressers. So, it could be inferred that, all the fourth and fifth grade students had adequate cognitive-linguistic and thematic knowledge about the story. Compared to the present study, Mirza-Aghabeyk et al. [34] investigated the effect of Persian cuedspeech method on micro- and macrostructure components of story retelling in nine of sixth grade students with late CI (age implantation after the age 6) and concluded that the participants presented significant improvements in narrative's macrostructure features (e.g., main information, topic maintenance, and event sequencing), but they continuously had difficulties in using two conjunctive cohesion and syntax complexity components as microstructure features of narration [34].

The findings concerning within-group comparisons between spoken and written narrative tasks revealed that scores of spoken narrative, both for micro- and macrostructures, were a little greater than those of written narrative, but these differences were not statistically significant. This matter shows that the students had similar performance in both of the tasks. They observed the quantity and quality of written narrative as being similar to those of spoken narrative. These results are in agreement with other studies about T-unit lengths in words and SI on spoken and written narrative in English-speaking secondary school students. The ATL for spoken narrative has been reported to be insignificantly greater than that of written narrative during adolescence [35]. Researchers have also reported that the SI is higher in oral samples rather than written ones. They concluded that the SI must be at least 1.30 in narrative samples, or the SI in written narrative must be at least equal to that of spoken narrative; otherwise, intervention programs shall be taken to improve and increase the clauses and syntactic complexities [36]. The results showed that the mean of the SI for spoken and written samples in the three groups was more than 1.38 , with no statistically significant difference between the tasks. So, no intervention program was necessary for the students. On the other hand, it might be stated that both types of narrative samples can elicit the same possibilities for the fourth and fifth grade students (even those with hearing impairments) to evaluate their written composition or spoken narrative skills.

The second main aim of this study was to within-between compare students' narrative skills based on their group, sex, hearing age, and educational grades. When taken as a factor, the group can influence outcomes of all of the narrative microstructures, whether primarily or in the form of interactions with other factors. Because there was a significant interaction effect of group $\times$ hearing age $\times$ educational level on the ATL, and there was a significant interaction effect of group $\times \operatorname{sex} \times$ educational level on the number of cohesive markers, narrative cohesion percentage, and accuracy performance percentage, so it can be stated that the fifth grade TH students had the best scores in the ATL, and the fifth grade TH girl students had the highest scores in the use of cohesive markers, narrative cohesion percentage, and accuracy performance percentage. Additionally, factor analysis detected a sex $\times$ educational level interaction effect on macrostructures of spoken narrative and written narrative. It means that, the fifth grade girl students had the best scores in main information presentation, story topic maintenance, and temporal observance of the sequence of events. Despite the differences in hearing health versus hearing disorders, hearing deprivation in two hearing-impaired groups, and more experience of discourse 
confrontation for TH students that might explain the findings, exact cause(s) of the girls' greater scores in most of micro- and macrostructures of narration are not easily explicable. One probable reason for the difference between girls and boys might be that the girls are more assertive and talkative than boys, so that girls in comparison with boys usually present explanations in further details about a subject [37] and their discourse is expected to have more lexical and clausal diversity than that of boys. Also, another explanation may be that, as opposed to boys, girls tend to see storytelling as a pleasing work and are culturally lean to role-play based on real or fiction stories. However, this finding needs further studies in future.

Findings showed that hearing impairment may limit microstructures of spoken/written narratives in CI and HA students, as compared to $\mathrm{TH}$ peer, and they are yet to be fully mastered in these tasks. It is essential that, in mainstream schools, the students with hearing impairments should receive additional trainings about microstructure components of morphology and syntax such as adverbs, auxiliary verbs, and conjunctions. In this regard, teachers and speech therapists must pay further attention to provide HA students (especially boys) with trainings on storytelling and written composition because this group of students exhibited the lowest scores in the comparisons made in the present research.

\section{CONFLICT OF INTEREST}

No potential conflict of interest relevant to this article was reported.

\section{ACKNOWLEDGMENTS}

The authors wish to thank Dr. Salimeh Jafari for giving permission us to use "The Playful Little Elephant" story.

This work was supported by a grant from the Hamadan University of Medical Sciences and Health Services, Deputy of Research (Grant Reference No. 9509025097), Hamadan, Iran.

\section{REFERENCES}

1. van Wieringen A, Wouters J. What can we expect of normally-developing children implanted at a young age with respect to their auditory, linguistic and cognitive skills? Hear Res. 2015 Apr;322:171-9.

2. Firoozbakht M, Mahmoudian S, Alaeddini F, Esmaeilzadeh M, Rafiei M, Firouzbakht A, et al. Community-based newborn hearing screening programme for early detection of permanent hearing loss in Iran: an eight-year cross-sectional study from 2005 to 2012. J Med Screen. 2014 Mar;21(1):10-7.

3. Connor CM, Craig HK, Raudenbush SW, Heavner K, Zwolan TA. The age at which young deaf children receive cochlear implants and their vocabulary and speech-production growth: is there an added value for early implantation? Ear Hear. 2006 Dec;27(6):628-44.

4. Zamani P, Weisi F, Ravanbakhsh M, Lotfi G, Rezaei M. Combined gestures and auditory-verbal training for comprehension and production of verbs in deaf children. Indian J Otolaryngol. 2016;22(4): 243-7.

5. Spencer LJ, Barker BA, Tomblin JB. Exploring the language and literacy outcomes of pediatric cochlear implant users. Ear Hear. 2003 Jun;24(3):236-47.

6. Iwasaki S, Nishio S, Moteki H, Takumi Y, Fukushima K, Kasai N, et al. Language development in Japanese children who receive cochlear implant and/or hearing aid. Int J Pediatr Otorhinolaryngol. 2012 Mar;76(3):433-8.

7. Zamani P, Rahmanirasa A, Weisi F, Valadbeigi A, Farahani F, Rezaei M.Vowel production in persian deaf children with cochlear implant: is the age of implantation an important factor? Indian J Otolaryngol Head Neck Surg. 2014 Dec;66(4):407-13.

8. Rezaei M, Emadi M, Zamani P, Farahani F, Lotfi G. Speech intelligibility in Persian hearing impaired children with cochlear implants and hearing aids. J Audiol Otol. 2017 Apr;21(1):57-60.

9. Justice LM, Bowles R, Pence K, Gosse C. A scalable tool for assessing children's language abilities within a narrative context:The NAP (Narrative Assessment Protocol). Early Child Res Q. 2010;25(2): 218-34.

10. Nippold MA, Taylor CL. Judgments of idiom familiarity and transparency: a comparison of children and adolescents. J Speech Lang Hear Res. 2002 Apr;45(2):384-91.

11. Paul R. Language disorders from infancy through adolescence: assessment and intervention. 5th ed. St. Louis (MO): Mosby Elsevier; 2007.

12. Kim YS, Al Otaiba S, Wanzek J. Kindergarten predictors of third grade writing. Learn Individ Differ. 2015 Jan;37:27-37.

13. Reuterskiold C, IbertssonT, Sahlen B. Venturing beyond the sentence level: narrative skills in children with hearing loss. Volta Rev. 2010; 110(3):389-406.

14. Luckner JL, Handley CM.A summary of the reading comprehension research undertaken with students who are deaf or hard of hearing. Am Ann Deaf. 2008;153(1):6-36.

15. Yoshinaga-Itano C, Downey DM. Analyzing deaf or hard-of-hearing students' written metacognitive strategies and story-grammar propositions. Volta Rev. 1996;98(1):63-4.

16. Sharifi A, Arefi M, Vajargah KF, Kakojoibari AA. Planning and validating a writing skill curriculum for hearing-impaired students in primary school system of Iran. Audit Vestib Res. 2016 Sep;25(3): 175-82.

17. Rezaei M, Rashedi V, Morasae EK. Reading skills in Persian deaf children with cochlear implants and hearing aids. Int J Pediatr Otorhinolaryngol. 2016 Oct;89:1-5.

18. Kormos J. Task complexity and linguistic and discourse features of narrative writing performance. J Second Lang Writ. 2011 June; 20(2):148-61.

19. Zamani P, Ravanbakhsh M, Weisi F, Rashedi V, Naderi S, Hosseinzadeh A, et al. Effect(s) of language tasks on severity of disfluencies in preschool children with stuttering. J Psycholinguist Res. 2017 Apr; 46(2):261-9.

20. Berninger VW, Abbott RD, Abbott SP, Graham S, Richards T.Writing and reading: connections between language by hand and language by eye. J Learn Disabil. 2002 Jan-Feb;35(1):39-56.

21. Dockrell JE, Lindsay G, Connelly V. The impact of specific language impairment on adolescents' written text. Except Child. 2009 July; 75(4):427-46.

22. Razavieh A, Shahim S. Retest reliability of the Wechsler preschool and primary scale of intelligence restandardized in Iran. Psychol Rep. 1990 Jun;66(3 Pt 1):865-6.

23. Heydari S, Torabi Nezhad F, Agha Rasouli Z, Hoseyni F. Develop- 
ment of speech intelligibility measurement test for 3 to 5 years old normal children. Bimonthly Audiol. 2011;20(1):47-53.

24. Hasanzadeh S, Minaii A. Adaptation and normalization of language development test TOLD-P: 3 for Persian-speaking children of Tehran: part 2. Res Except Child. 2002;1:119-34.

25. Berman RA. Narrative competence and storytelling performance: how children tell stories in different contexts. J Narrat Life Hist. 1995;5(4):285-313.

26. Rumpf AL, Kamp-Becker I, Becker K, Kauschke C. Narrative competence and internal state language of children with Asperger Syndrome and ADHD. Res Dev Disabil. 2012 Sep-Oct;33(5):1395-407.

27. Bliss LS, McCabe A, Miranda AE. Narrative assessment profile: discourse analysis for school-age children. J Commun Disord. 1998 JulAug;31(4):347-62 .

28. Jafari S, Agharasouli Z, Modaresi Y, Kamali M. Developing a story retelling test for the assessment of language structure in Persianspeaking children. Bimonthly Audiol. 2012;21(3):51-61.

29. Bartko J. On various intraclass correlation reliability coefficients. Psychol Bull. 1976 Sep;83(5):762-65.

30. Pakulski LA, Kaderavek JN. Narrative production by children who are deaf or hard of hearing: the effect of role-play. Volta Rev. 2001; 103(3):127-39.
31. Levorato MC, Roch M, Nesi B. A longitudinal study of idiom and text comprehension. J Child Lang. 2007 Aug;34(3):473-94.

32. Adams C, Clarke E, Haynes R. Inference and sentence comprehension in children with specific or pragmatic language impairments. Int J Lang Commun Disord. 2009 May-Jun;44(3):301-18.

33. Nicastri M, Filipo R, Ruoppolo G, Viccaro M, Dincer H, Guerzoni L, et al. Inferences and metaphoric comprehension in unilaterally implanted children with adequate formal oral language performance. Int J Pediatr Otorhinolaryngol. 2014 May;78(5):821-7.

34. Mirza-Aghabeyk S, Movallali G, Taheri M, Esteki M. The effect of cued speech on story retelling in late implanted prelingual hearing impaired students. Audit Vestib Res. 2015;24(1):25-30.

35. Scott CM, Windsor J. General language performance measures in spoken and written narrative and expository discourse of school-age children with language learning disabilities. J Speech Lang Hear Res. 2000 Apr;43(2):324-39.

36. Nippold MA. Language development during the adolescent years: aspects of pragmatics, syntax, and semantics. Top Lang Disord. 2000; 20(2):15-28

37. Owens RE Jr. Language development: an introduction. 9th ed. Harlow: Pearson; 2016 